\title{
Effect of peptones on the ability of plant pathogenic bacteria to grow on media supplemented with copper sulphate
}

\author{
D.A. Cornish, M.M. Schipper, J.M. Oldham and J.L. Vanneste \\ The New Zealand Institute for Plant \& Food Research Limited, Ruakura Research Centre, \\ Private Bag 3123, Hamilton 3240, New Zealand \\ Corresponding author: Joel.Vanneste@plantandfood.co.nz
}

\begin{abstract}
The extensive use of copper compounds for control of bacterial plant pathogens could lead to selecting strains of the pathogens that are copper-resistant. The ability to grow on a medium supplemented with copper, and therefore the concentration of copper to which bacterial strains are resistant, depends on the composition of the medium used for the test. The effects of different peptones (casitone and proteose peptone No. 3) and different media on the ability of strains of Pseudomonas syringae to grow in presence of copper were determined. Similar results were obtained when casitone was substituted with proteose peptone No. 3 in casitone yeast extract medium, but not when those two peptones were interchanged in King's B medium. In water, casitone allowed strains of P. syringae pv. actinidiae (Psa) to grow in the presence of higher amounts of copper than proteose peptone No. 3 did. In all cases, resistance to copper was increased with increased peptone concentration.
\end{abstract}

Keywords Pseudomonas syringae pv. actinidiae, Pseudomonas syringae, copper resistance, ammonium sulphate, bacterial canker of kiwifruit.

\section{INTRODUCTION}

Copper compounds are some of the few compounds available for control of plant pathogenic bacteria, leading to their extensive use in horticulture. However, overuse of copper can lead to selection of copper-resistant strains of bacteria. Copper-resistant strains of Pseudomonas syringae pv. actinidiae (Psa), the causal agent of bacterial canker of kiwifruit, and of other $P$. syringae affecting stonefruit have been isolated in New Zealand (Colombi et al. 2017; Vanneste et al. 2008; Vanneste et al. 2005; Vanneste \& Voyle 2003).

Copper-resistant strains are usually identified by their ability to grow on agar plates supplemented with different concentrations of copper sulphate. However, the ability to grow on a medium supplemented with copper and the concentration of copper to which bacterial strains are resistant depends on the composition of the medium used for the test (Menkissoglu \& Lindow 1991; Pernezny et al. 2008). Several constituents of growing media have been found to influence the ability of copper to inhibit or kill bacteria, including organic compounds such as sugars and amino acids (Geider 1999; Menkissoglu \& Lindow 1991). Bacterial strains 
resistant to copper on one medium can appear sensitive when using a different medium (Pernezny et al. 2008). Therefore, we became interested in understanding the effects of different constituents of media on the ability of copper to kill bacteria.

Peptones are widely used as sources of nitrogen and amino acids in bacteriological agar media. Peptones can be of plant or animal origin and are usually obtained by the enzymatic digestion of milk, meat products or plant extracts. We aimed to determine the influence of peptones on the ability of copper to inhibit some plant pathogenic bacteria. Two peptones - casitone, a casein trypsin digest; and proteose peptone No. 3, an animal casein polypeptone - were used at different concentrations in different bacteriological media to establish a correlation between peptone concentrations and concentrations of copper needed to kill coppersensitive or copper-resistant bacteria.

\section{MATERIALS AND METHODS}

\section{Strains and media}

The source and date of isolation of the strains used in this study are presented in Table 1. All the strains have been isolated as part of studies undertaken at Plant \& Food Research, except RT594 which was isolated by Verified Laboratory Services (VLS) at Te Puke. Most experiments were carried out with Psa 10627, which has been found to be copper sensitive and Psa RT594, which is copper resistant (J Vanneste, unpubl. data). The media used were King's B (KB) (King et al. 1954), sucrose peptone agar (SPA) (Hayward 1960), and casitone yeast extract (CYE), as described in the Bacteriological Analytical Manual (US Food and Drug Administration 1998) or by Andersen et al. (1991). The CYE medium described in the Bacteriological Analytical Manual contains 30 g/litre casitone, while the CYE modified by Andersen contains only 1.7 g/litre casitone. When needed, concentrations of Bacto $^{\mathrm{TM}}$ Proteose Peptone No. 3 or Bacto ${ }^{\mathrm{TM}}$ Casitone (Difco Laboratories, MD) were modified from those given in the recipes; concentrations of both compounds ranged from $0.17 \mathrm{~g} /$ litre to $40 \mathrm{~g} /$ litre.
When necessary, media were supplemented with ammonium phosphate at $1 \mathrm{~g} /$ litre. When needed, copper sulphate was added to media in which the concentration of peptone was modified at the following concentrations: $0.4,1,2,4$ or $8 \mathrm{mM}$. A concentration of $6 \mathrm{mM}$ of copper sulphate was used only in CYE containing 20g/litre of casitone. In the other experiments, copper sulphate was added at one of the following concentrations: $0.16,0.32,0.4,0.64,1,1.28,2,2.56,4,8$ or $10 \mathrm{mM}$.

\section{Determining copper resistance on agar plates}

Copper resistance was defined as the ability of a strain to develop isolated colonies in the time it took for isolated colonies of the same strain to develop on the same medium without copper. Usually plates were incubated at $28^{\circ} \mathrm{C}$ for 3 days before recording results. In some cases, limited growth was visible where the strains were streaked, but without developing into isolated colonies; these were recorded as negative results. At least three replicates were conducted for each medium and each copper concentration. The most representative results are presented.

\section{Determining copper resistance in aqueous solutions}

The effects of organic compounds present on kiwifruit leaves and of different concentrations of peptone were assessed in aqueous solutions. Up to 12 concentrations of proteose peptone No. 3 or casitone $(0.17,0.4,0.8,1.2,1.7,2,3.4,5$, $10,15,20$ and $40 \mathrm{~g} /$ litre) were dissolved in water prior to autoclaving. Five-millilitre aliquots were supplemented with copper sulphate to obtain final concentrations ranging from 0 to $8 \mathrm{mM}$. Bacterial strains were inoculated into these solutions at a final concentration of $\sim 2 \times$ $10^{7}$ colony forming units (cfu)/mL. After $24 \mathrm{~h}$ of incubation at $28^{\circ} \mathrm{C}$, three $10-\mu \mathrm{L}$ drops from each sample were pipetted onto $\mathrm{KB}$ agar to determine the concentration of copper which killed the bacterial strains.

Ten kiwifruit leaves of Actinidia chinensis var. chinensis 'Zesy002' (also known as Gold3) were washed in $100 \mathrm{~mL}$ sterile water, filter sterilised $(0.22 \mu \mathrm{m})$ before being dispensed in $5-\mathrm{mL}$ 
Table 1 Strains of Pseudomonas syringae pv. actinidiae and Pseudomonas syringae used in this study.

\begin{tabular}{|c|c|c|c|c|}
\hline Strain & $\begin{array}{l}\text { Year of } \\
\text { Isolation }\end{array}$ & Host Plant & $\begin{array}{l}\text { Copper } \\
\text { Resistant }\end{array}$ & Reference \\
\hline $\begin{array}{l}\text { P. syringae pv. actinidiae } \\
10627\end{array}$ & 2010 & $\begin{array}{l}\text { Actinidia chinensis } \\
\text { var. chinensis }\end{array}$ & No & $\begin{array}{l}\text { Vanneste et al. } \\
(2013)\end{array}$ \\
\hline $\begin{array}{l}\text { P. syringae pv. actinidiae } \\
\text { RT594 }\end{array}$ & 2015 & $\begin{array}{l}\text { A. chinensis var. } \\
\text { chinensis }\end{array}$ & Yes & This study \\
\hline $\begin{array}{l}\text { P. syringae pv. actinidiae } \\
\text { SR164 }\end{array}$ & 2015 & $\begin{array}{l}\text { A. chinensis var. } \\
\text { chinensis }\end{array}$ & Yes & This study \\
\hline $\begin{array}{l}\text { P. syringae pv. actinidiae } \\
11444\end{array}$ & 2011 & $\begin{array}{l}\text { A. chinensis var. } \\
\text { deliciosa }\end{array}$ & No & This study \\
\hline P. syringae SF $2 / 2-10$ & 2005 & Nectarine & No & This study \\
\hline P. syringae SF 18C-1 & 2005 & Nectarine & Yes & This study \\
\hline P. syringae SF 19/5-14 & 2005 & Summerfruit & No & This study \\
\hline P. syringae SF 18/3-11 & 2005 & Summerfruit & Yes & This study \\
\hline
\end{tabular}

aliquots. Those aliquots were supplemented with copper sulphate ranging from 0 to $1 \mathrm{mM}$. Those solutions were inoculated with bacterial suspensions to obtain a final concentration of $\sim 2$ $\times 10^{7} \mathrm{cfu} / \mathrm{mL}$. As described above, after $24 \mathrm{~h}$ of incubation at $28^{\circ} \mathrm{C}$, three $10-\mu \mathrm{L}$ drops from each sample were pipetted onto $\mathrm{KB}$ agar to determine the concentration of copper which killed the bacterial strains. Each experiment was replicated at least three times; the most representative results are presented.

\section{RESULTS}

\section{Influence of the growing medium on copper resistance}

The highest concentrations of copper on which strains of $P$. syringae pv. actinidiae or P. syringae could grow when streaked on media routinely used to grow bacteria are given in Table 2. The concentration of copper sulphate necessary to kill strains of Pseudomonas varied widely depending on the medium used. Strains were always able to grow in the presence of higher concentrations of copper sulphate when grown on CYE containing $30 \mathrm{~g} /$ litre casitone than when grown on $\mathrm{KB}$ or CYE containing $1.7 \mathrm{~g}$ casitone.

\section{Effect of peptone concentration on copper resistance}

To determine the effect of peptone concentration on the susceptibility of bacteria to copper, the concentrations of proteose peptone No. 3 in $\mathrm{KB}$ medium and of casitone in CYE medium were modified from $1.7 \mathrm{~g} /$ litre to $40 \mathrm{~g} /$ litre. In CYE medium, the copper-resistant strain RT594 always grew in presence of a higher concentration of copper than the copper-sensitive strain Psa 10627. Both strains grew in the presence of higher concentrations of copper when the concentrations of peptone were higher (Figure 1). This was also true for the $\mathrm{KB}$ medium, except when proteose peptone No. 3 was added at a concentration of 40g/litre. In this case, both Psa 10627 and RT594 were inhibited by copper sulphate above $2 \mathrm{mM}$.

To confirm that the ability of the bacteria to grow in the presence of higher concentrations of copper is linked to the peptone concentration, the same two strains (Psa 10627 and RT594) were incubated in water containing different concentrations of casitone and different concentrations of copper. The copper-resistant strain RT594 could survive at higher concentrations of copper than the copper-sensitive strain Psa 10627 below 15 g/ litre proteose peptone No. 3, and below $10 \mathrm{~g} /$ 
Table 2 Highest concentrations of copper sulphate $(\mathrm{mM})$ at which different strains of Pseudomonas syringae can grow.

\begin{tabular}{lcccc}
\hline \multicolumn{5}{c}{ Concentration of copper sulphate (mM) } \\
\hline Strains & $\begin{array}{c}\text { King's B } \\
\text { medium }\end{array}$ & $\begin{array}{c}\text { Casitone Yeast } \\
\text { extract (CYE) }\end{array}$ & $\begin{array}{c}\text { Casitone Yeast } \\
\text { extract }^{\mathrm{b}}\end{array}$ & $\begin{array}{c}\text { Sucrose } \\
\text { peptone agar }\end{array}$ \\
\hline 10627 & 1 & 0.32 & 4 & 1 \\
RT594 & 8 & 1 & $>10$ & 4 \\
SR164 & 8 & 0.64 & $>10$ & 2 \\
11444 & 1 & 0.16 & 4 & 1 \\
SF 18c-1 & 2 & 0.64 & $>10$ & 2 \\
SF 19/5-14 & 1 & 0.16 & 2.56 & 0.4 \\
SF 18/3-11 & 8 & 1.28 & $>10$ & 4 \\
SF 2/2-10 & 1 & 0.32 & 6 & 1 \\
\hline
\end{tabular}

a: CYE as described by Anderson et al. (1991)

b: CYE as described in Bacteriological Analytical Manual (1998)
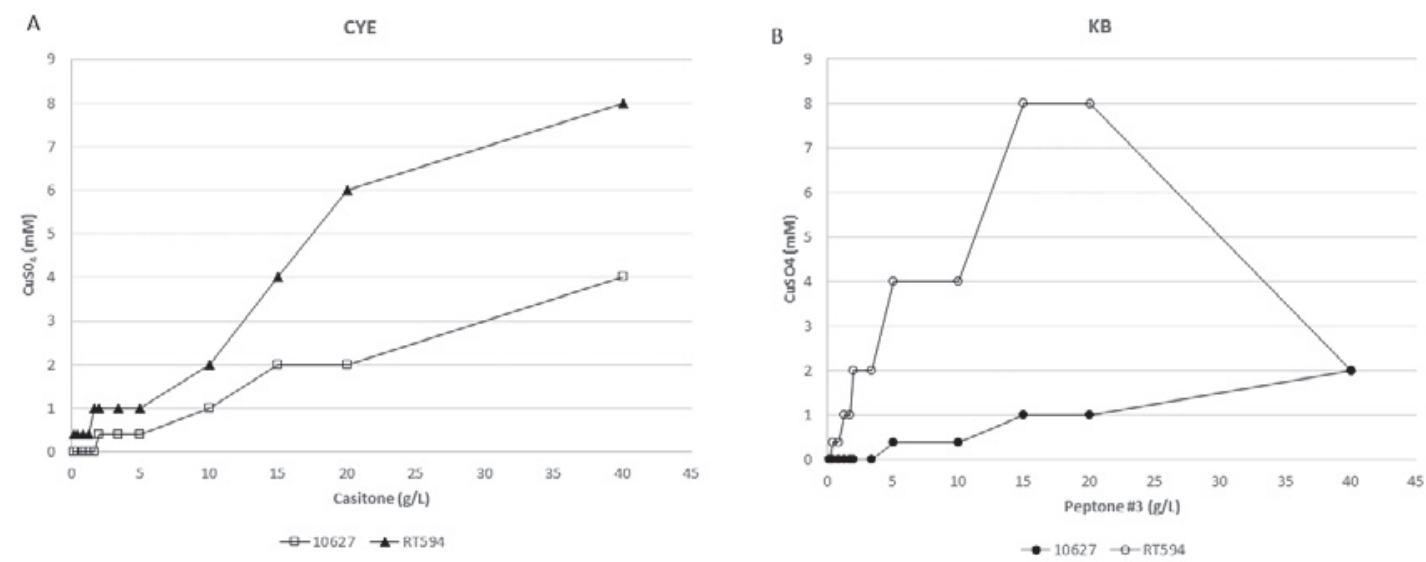

Figure 1 Highest concentrations of copper at which Pseudomonas syringae pv. actinidiae 10627 or RT594 could grow on casitone yeast extract (CYE) medium containing different concentrations of casitone (panel A), or on King's B medium containing different concentrations of proteose peptone No. 3 (panel B).

litre casitone, (Figure 2). However, above those concentrations, the two strains could grow at the same copper concentration. Casitone enabled the bacteria to survive at higher concentrations than proteose peptone No. 3 did. This is the opposite of the results obtained using CYE medium with different concentrations of casitone or
KB medium with different concentrations of proteose peptone No. 3. These results indicate that the concentration of peptone influences the degree of resistance to copper but that the other constituents of the medium have also an influence on the bioavailability of copper. 


\section{Effect of the type of peptone on copper resistance}

To determine the relative importance of the source of peptone or of the other constituents of the media, proteose peptone No. 3 was replaced by casitone in a set of KB medium agar plates supplemented with different peptone and copper sulphate concentrations. Similarly, casitone was replaced by proteose peptone No. 3 in a set of CYE medium agar plates supplemented with different peptone and copper sulphate concentrations. On CYE medium, casitone allowed both strains to grow in presence of a greater concentration
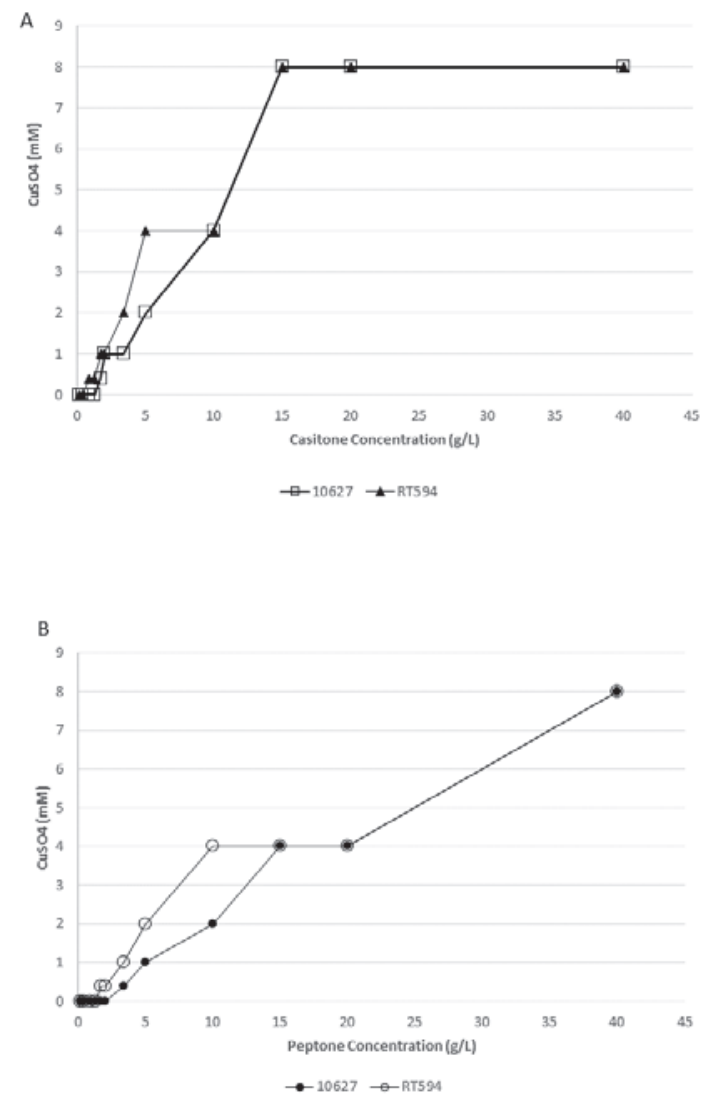

Figure 2 Highest concentrations of copper at which Pseudomonas syringae pv. actinidiae 10627 or RT594 could survive in the presence of casitone (panel A) or proteose peptone No. 3 (panel B). of copper sulphate than proteose peptone No. 3 at the same concentration (Figure 3A). This was also true for Psa 10627 on KB medium (Figure 3B). However, for RT594, the source of peptone in KB medium did not influence the concentration of copper at which the strain could grow. Except as noted earlier, at a concentration of $40 \mathrm{~g} /$ litre of proteose peptone No. 3 RT594 could not grow when the concentration of copper sulphate was above $2 \mathrm{mM}$.
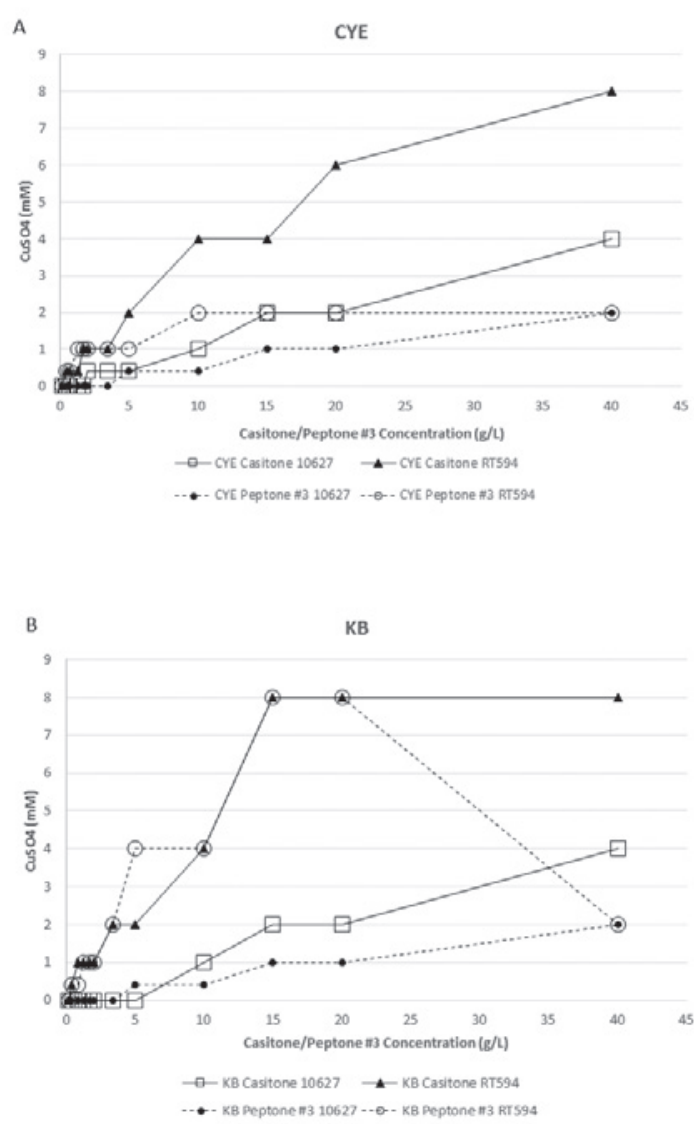

Figure 3 Highest concentrations of copper at which Pseudomonas syringae pv. actinidiae 10627 or RT594 could survive on a casitone yeast extract (CYE) agar plate with casitone or proteose peptone No. 3 (panel A), or on King's $\mathrm{B}$ agar plates with casitone or proteose peptone No. 3 (panel B). 


\section{Influence of kiwifruit leaf washings on copper resistance}

The copper-sensitive strain Psa 10627 was killed by the same concentration of copper when incubated in either water alone or in aqueous kiwifruit leaf washings. This result indicates that those washings did not contain organic compounds that interfered with the ability of copper to kill Psa, or that they were not in concentrations high enough to interfere with the action of the copper.

\section{Effect of ammonium phosphate on copper resistance}

When all peptones were replaced by ammonium phosphate, the strains did not grow (data not shown). Ammonium phosphate did provide a nitrogen source, but was probably not providing the amino acids necessary for the strains to grow. Adding low amounts of proteose peptone No. 3 ( $5 \mathrm{~g} /$ litre $)$ as a source of amino acids to the KB medium supplemented with ammonium phosphate enabled both the Psa 10627 and RT594 strains to develop isolated colonies within 72 hours. On that medium, the copper-sensitive Psa 10627 strain could not grow in presence of more than $0.32 \mathrm{mM}$ of copper, while RT594 could grow in presence of at least $4 \mathrm{mM}$ of copper (Table 3). Other copper resistant strains were inhibited by $4 \mathrm{mM}$ of copper but could grow in presence of $2 \mathrm{mM}$ of copper.

Table 3 Highest concentration of copper sulphate at which different strains of Pseudomonas syringae can grow on modified King's B medium supplemented with ammonium phosphate.

\begin{tabular}{lc}
\hline Strain & $\begin{array}{c}\text { Highest concentration } \\
\text { of } \mathrm{CuSO}_{4}(\mathrm{mM})\end{array}$ \\
\hline 10627 & 0.32 \\
RT594 & 4.0 \\
SR164 & 2.0 \\
11444 & 0.32 \\
SF 2/2-10 & 0.32 \\
SF 18C-1 & 2.0 \\
SF 19/5-14 & 0.32 \\
SF 18/3-11 & 4.0 \\
\hline
\end{tabular}

\section{DISCUSSION}

Overuse of copper-based products for the control of plant pathogenic bacteria can lead to resistance to copper, potentially leading to a loss of control using those products. Resistance to copper has been found in a number of plant pathogenic bacteria in New Zealand (Colombi et al. 2017; Vanneste et al. 2008; Vanneste et al. 2005). Our results confirm that a strain can appear copper sensitive or copper resistant depending on the medium used to carry out the test. The main aim of this research was to determine the effects of different growing media and the effects of different peptones on the ability of bacteria to grow in the presence of copper.

Peptones were targeted because previous studies have demonstrated that amino acids and other organic compounds interfere with the ability of copper to kill plant pathogenic bacteria (Geider 1999; Menkissoglu \& Lindow 1991). In this study, strains of Psa and other P. syringae could grow in the presence of higher concentrations of copper when the concentration of peptone increased. That peptones were the main constituent which affected the toxicity of copper was further demonstrated by determining the effects of different peptones in water on the abilities of both a copper-sensitive or a copperresistant strain of Psa to grow. Those results are consistent with the findings that ammonium groups of some amino acids bind to copper and limit its bioavailability (Geider 1999).

Replacing peptones with ammonium phosphate has been used to detect bacteria that can use this compound as a nitrogen source (Qin et al. 2006). Plant pathogenic bacteria such as $P$. syringae also need some amino acids, and ammonium phosphate cannot be used instead of peptones. However, a mixture of peptone and ammonium phosphate allows $P$. syringae to grow to isolated colonies within $72 \mathrm{~h}$ (data not shown). In such a medium, a small amount of copper stays bioavailable and therefore copper-sensitive strains were killed when copper concentrations reached $0.32 \mathrm{mM}$. Copper-resistant strains could grow in the presence of relatively high amounts of copper, presumably because most of the 
copper was bound to the ammonium groups.

A very good correlation exists between peptone concentration and the concentration of copper a strain can tolerate. Therefore, results of copper resistance obtained by different laboratories or results obtained at different times can be compared. However, peptones are not the only constituents of bacteriological media to interfere with copper, and therefore caution has to be exercised when constituents other than peptones differ among media.

\section{ACKNOWLEDGEMENTS}

We thank Zespri Group Limited and Kiwifruit Vine Health for financial support, and we thank Fazeelath Basith for technical support.

\section{REFERENCES}

Andersen GL, Menkissoglou O, Lindow SE 1991. Occurrence and properties of copper-tolerant strains of Pseudomonas syringae isolated from fruit trees in California. Phytopathology 81(6): 648-656.

Colombi E, Straub C, Kunzel S, Templeton MD, McCann HC, Rainey PB 2017. Evolution of copper resistance in the kiwifruit pathogen Pseudomonas syringae pv. actinidiae through acquisition of integrative conjugative elements and plasmids. Environmental Microbiology. In press.

Geider K 1999. Interference of copper sulphate in growth of Erwinia amylovora. Journal of Phytopathology-Phytopathologische Zeitschrift 147(9): 521.

Hayward AC 1960. A Method for characterizing Pseudomonas solanacearum. Nature 186(4722): 405-406.
King EO, Ward MK, Raney DE 1954. Two simple media for the demonstration of pyocyanin and fluorescin. Journal of Laboratory Clinical Medicine 44: 301-307.

Menkissoglu O, Lindow SE 1991. Relationship of free ionic copper and toxicity to bacteria in solutions of organic compounds. Phytopathology 81(10): 1258-1263.

Pernezny K, Nagata R, Havranek N, Sanchez J 2008. Comparison of two culture media for determination of the copper resistance of Xanthomonas strains and their usefulness for prediction of control with copper bactericides. Crop Protection 27(2): 256-262.

Qin J, Xiao Z, Ma C, Xie N, Liu P, Xu P 2006. Production of 2,3-butanediol by Klebsiella Pneumoniae using glucose and ammonium phosphate. Chinese Journal of Chemical Engineering 14(1): 132-136.

US Food and Drug Administration 1998. Bacteriological Analytical Manual 8th Edition.

Vanneste JL, Cornish DA, Yu J, Boyd RJ, Morris CE 2008. Isolation of copper and streptomycin resistant phytopathogenic Pseudomonas syringae from lakes and rivers in the central North Island of New Zealand. New Zealand Plant Protection 61: 80-85.

Vanneste JL, McLaren GE, Yu J, Cornish DA, Boyd $\mathrm{R}$ 2005. Copper and streptomycin resistance in bacterial strains isolated from stone fruit orchards in New Zealand. New Zealand Plant Protection 58: 101-105.

Vanneste JL, Voyle MD 2003. Genetic basis of copper resistance in New Zealand strains of Pseudomonas syringae. New Zealand Plant Protection 56: 109-112. 